\title{
Flipgrid: A Pathway to Enhance Students' Speaking Performance
}

\author{
Della Nuridah Kartika Sari Amirulloh, Ika Lestari Damayanti, Ellen Citraningrum*
}

Faculty of Language and Literature Education, Universitas Pendidikan Indonesia

${ }^{*}$ Corresponding author. Email: ellencitra@student.upi.edu

\begin{abstract}
The aim of the study was to explore the use of Flipgrid's features as students' learning support to improve their speaking skills. Utilizing a case study, the present research involved nineteen students of the Department of English Education in a public university in Bandung, West Java. The data were obtained from students' speaking video and interviews. The students speaking videos were analysed using one of the existing speaking rubrics available with several modifications. The result indicated that using Flipgrid might improve the students' speaking skills in several aspects, such as fluency, pronunciation, and gestures.
\end{abstract}

Keywords: Flipgrid, speaking performance, online learning

\section{INTRODUCTION}

EFL learners, no matter how much they learn the English language, often face many difficulties in communication. A study conducted by Al-Jamal and AlJamal (2014) showed that most EFL students involved in the study are quite dissatisfied with their language performance, which only emphasizes linguistic ability rather than communicative abilities. There are several major external and internal factors contributing to these. External factors are mostly related to the teachers' ability to manage teaching-learning processes, such as classroom management, teaching strategy, and material mastery (Mahmoudi \& Mahmoudi, 2015). Meanwhile, the internal factors are factors that come from the students themselves. Students are nervous and afraid when they want to talk or communicate with their classmates using English (Tuan \& Mai, 2015). The finding is in line with Alharbi (2015) who found that students used their native language to communicate. Only a small percentage of students that use English for their daily communications. Therefore, to improve students' speaking skills in English, teachers may use various techniques, such as discussions, simulations, role-play, brainstorming, storytelling, and describing pictures (Kayi, 2006). Those activities are usually carried out face-to-face in the classroom.

However, due to COVID-19, various routine activities such as face-to-face meetings in class, and academic guidance processes become obstructed because the Indonesian government has established social distancing policies to minimize the spread of COVID-19. It has caused schools and colleges to close almost completely. The closure of schools and colleges affects more than $90 \%$ of the world's student population (UNESCO, 2020). Moreover, in response to schools and colleges closure, UNESCO (2020) recommended using distance education programs and educational applications or platforms that teachers and schools can use to reach the students regardless of distance. Therefore, implementing online learning is a way that can be done to overcome those problems.

Nowadays, online learning is considered as one of the best choices for the world of education. Various educational institutions are now starting to use technology and implementing online learning systems to support learning activities that can be accessed anywhere. For example, a public University in Bandung, West Java applied the system where the learning activity is conducted online by using some platforms such as, Google Classroom, Edmodo, Zoom, Flipgrid and many more. In accordance with Dhull and Sakshi (2017), online learning utilizes many technologies to support education such as email, web, new groups texts, chat, audio, and video conferencing, which is connected through a computer network or the internet. There are many platforms or online media that can be used in online learning. One of them is Flipgrid, which is used in speaking classes in English education department. Flipgrid is a free platform made for educational purposes 
for students to post a video response to teacher questions (MacIsaac, 2020). Flipgrid is a smooth and practical tool useful for building a student-centred learning community (Theoris, 2017). Flipgrid is accessible to all and is not restricted to one community only (Dettinger, 2018).

Several studies have been conducted to provide more perspectives into Flipgrid's contributions to online learning. A study investigated by Tuyet and Khang (2020) analysed the use of Flipgrid to helps EFL high school students reduce their anxiety about learning English and evaluate the learners' attitudes towards its applications. The study involved a quasi-experimental approach and a mixed method with 60 EFL tenth grade students in the Mekong Delta. In this study, three research instruments were used: the adapted Foreign Language Classroom Anxiety Scale (FLCAS), the interviews, and questionnaires. The results have shown that EFL high school students' anxiety level in learning English speaking after learning Flipgrid has decreased. Besides, most learners also expressed their optimistic attitudes towards the use of Flipgrid in English-speaking learning. They anticipated Flipgrid to be used regularly to make English-speaking education more engaging.

Another study conducted by Keiper, White, Carlson, and Lupinek (2020), this study is a mixed approach, an exploratory study designed to analyse the Flipgrid's effectiveness. Flipgrid is an online video community forum learning tool that can be used in business courses in the HyFlex delivery method on a smartphone. The research has been conducted with ten undergraduate and graduate business education courses by using a set of questionnaires, both Likert-style and open-ended questions. Findings indicate that Flipgrid is a useful learning platform, and students considered Flipgrid useful and helpful to them. As stated by several studies, Flipgrid is a useful platform for online learning. Discussion across the community is spread fairly by using the Flipgrid, and it can improve speaking time, pronunciation, and collaboration among students. However, only a few studies discuss the use of Flipgrid for the students' speaking abilities, particularly in the EFL context. Most of the Flipgrid-related studies only investigated the students' perceptions of Flipgrid and its effect on students' motivation. Therefore, this research focuses on investigating the use of Flipgrid's features in order to help the students' speaking skills.

\section{METHOD}

This study is carried out using qualitative data, as this analysis is explicitly concerned with context rather than generalization (Creswell, 2012). Qualitative research is a methodology that allows the researchers to analyse the experience of individuals in detail, using different research methods such as in-depth interviews, focus group observation, content analysis, discussions, visual methods, and life histories or biographies (Hennink, Hutter, \& Bailey, 2020). The qualitative casestudy analysis was applied to investigate whether using the features of the Flipgrid could improve the students' speaking skills. A case study has been used since it helps the researcher perform research in small respondents (Emilia, 2009). The participants of this study were 19 undergraduate students who majored in English Education department in one public university in Bandung.

This research collected the data by using the speaking video submitted by students and interviews to provide a more in-depth description. The interview was conducted after the students' speaking video had been assessed and the scores added up. Six students were selected to be interviewed with the criteria two students who got the highest score, two students who got the average score and two students who got the lowest score. Interviews were carried out through the LINE platform in English. The researcher asked questions using voice notes and the interviewee also answered using voice notes so that they could be stored and listened to repeatedly for transcripts. Each student was given several questions related to the use of Flipgrid in their speaking class. The two data from the students' speaking video and interviews are combined through triangulation in the process of data collection. The students' speaking video was analysed using a combination of speaking rating scale by Harris (1969) and Anderson and Delmonico (2016). The video of the students provided information on the students' speaking abilities. The interview details can be used as a guide to help the interpretations of the students' speaking video. The interview's objective is to find out more about the students' speaking skills using Flipgrid features.

\section{FINDINGS AND DISCUSSION}

The topic investigated in the present study is concerned with students' speaking skills by using Flipgrid as a platform. The table below shows the students' overall scores from the five speaking video topics they have uploaded to Flipgrid. The students' speaking scores from the five topics above were added up and then ranked to determine the two students with the highest score, two students with the average score, and two students with the lowest score. The students Q, $\mathrm{R}$, and $\mathrm{S}$ were excluded from the ranking because they did not qualify to become study participants due to many missing scores. Therefore, the researcher chose S5 and S6 as the two students with the lowest score to replace students $\mathrm{R}$ and $\mathrm{S}$, which can be seen in Table 1 . As we can see in Table 2, the highest score in each topic gets 5 points. S1 gets the highest number of accumulated scores 22,5 and gets an average of 4,5. S2 got the total of 21 and average of 4,2 . 
Table 1. Students' Total Speaking Score

\begin{tabular}{|c|c|c|c|c|c|c|c|c|}
\hline \multirow{2}{*}{ Name } & \multicolumn{5}{|c|}{ TOPIC } & \multirow{2}{*}{ Total } & \multirow{2}{*}{ Rank } & \multirow{2}{*}{ Initial } \\
\hline & I'm a presenter & I'm a moderator & I'm an MC & Progress Test 2 & Presenting Essay & & & \\
\hline $\mathbf{A}$ & 4.5 & 4.0 & 4.3 & 4.8 & 4.8 & 22.5 & 1 & S1 \\
\hline B & 4.7 & 3.8 & 4.2 & 4.2 & 4.2 & 21.0 & 2 & S2 \\
\hline C & 4.5 & 4.2 & 4.0 & 3.8 & 3.8 & 20.3 & 3 & \\
\hline D & 4.5 & 3.8 & 4.0 & 3.7 & 4.0 & 20.0 & 4 & \\
\hline $\mathbf{E}$ & 3.8 & 4.2 & 3.8 & 4.0 & 3.8 & 19.7 & 5 & \\
\hline $\mathbf{F}$ & 3.8 & 3.7 & 3.8 & 3.8 & 4.3 & 19.5 & 6 & \\
\hline G & 4.0 & 3.8 & 3.8 & 4.0 & 3.7 & 19.3 & 7 & \\
\hline $\mathbf{H}$ & 4.0 & 4.2 & 4.0 & 3.8 & 3.2 & 19.2 & 8 & S3 \\
\hline I & 4.0 & 4.2 & 3.7 & 3.7 & 3.7 & 19.2 & 9 & S4 \\
\hline $\mathbf{J}$ & 3.5 & 3.8 & 3.7 & 3.5 & 3.8 & 18.3 & 10 & \\
\hline $\mathbf{K}$ & 3.5 & 3.7 & 3.7 & 3.8 & 3.5 & 18.2 & 11 & \\
\hline $\mathbf{L}$ & 3.7 & 3.8 & 3.5 & 3.7 & 3.3 & 18.0 & 12 & \\
\hline $\mathbf{M}$ & 3.7 & 3.5 & 3.7 & 3.7 & 3.3 & 17.8 & 13 & \\
\hline $\mathbf{N}$ & 3.8 & 3.5 & 3.7 & 3.7 & 3.2 & 17.8 & 14 & \\
\hline o & 3.5 & 3.3 & 3.5 & 4.0 & 3.0 & 17.3 & 15 & S5 \\
\hline $\mathbf{P}$ & 3.3 & 3.5 & 3.5 & 3.5 & 3.3 & 17.2 & 16 & S6 \\
\hline $\mathbf{Q}$ & 0.0 & 3.7 & 3.5 & 3.5 & 3.3 & 14.0 & 17 & \\
\hline $\mathbf{R}$ & 0.0 & 0.0 & 0.0 & 3.5 & 3.3 & 6.8 & 18 & \\
\hline $\mathbf{S}$ & 0.0 & 0.0 & 3.7 & 0.0 & 0.0 & 3.7 & 19 & \\
\hline
\end{tabular}

Table 2. S1-S5 Score from Each Topics

\begin{tabular}{|c|c|c|c|c|c|c|c|}
\hline \multirow{2}{*}{ Name } & \multicolumn{5}{|c|}{ TOPIC } & \multirow{2}{*}{ Total } & \multirow{2}{*}{ Rank } \\
\hline & I'm a presenter & I'm a moderator & I'm an MC & Progress Test 2 & Presenting Essay & & \\
\hline S1 & 4.5 & 4.0 & 4.3 & 4.8 & 4.8 & 22.5 & 1 \\
\hline $\mathrm{S} 2$ & 4.7 & 3.8 & 4.2 & 4.2 & 4.2 & 21.0 & 2 \\
\hline $\mathrm{S} 3$ & 4.0 & 4.2 & 4.0 & 3.8 & 3.2 & 19.2 & 8 \\
\hline S4 & 4.0 & 4.2 & 3.7 & 3.7 & 3.7 & 19.2 & 9 \\
\hline S5 & 3.5 & 3.3 & 3.5 & 4.0 & 3.0 & 17.3 & 15 \\
\hline
\end{tabular}

Table 3. Students Speaking Scores in a Topic

\begin{tabular}{|c|c|c|c|c|c|c|c|c|}
\hline \multicolumn{9}{|c|}{ I'M A MODERATOR IN A SEMINAR } \\
\hline \multirow[b]{2}{*}{ Name } & \multicolumn{6}{|c|}{ Speaking Aspects } & \multirow[b]{2}{*}{ Total } & \multirow[b]{2}{*}{ Average } \\
\hline & Pronunciation & Grammar & Vocabulary & Fluency & $\begin{array}{c}\text { Facial } \\
\text { Expression }\end{array}$ & Gesture & & \\
\hline $\mathrm{S} 1$ & 4 & 5 & 5 & 4 & 5 & 1 & 24 & 4.0 \\
\hline $\mathrm{S} 2$ & 4 & 5 & 5 & 4 & 3 & 2 & 23 & 3.8 \\
\hline $\mathrm{S} 3$ & 4 & 5 & 5 & 4 & 4 & 3 & 25 & 4.2 \\
\hline S4 & 4 & 5 & 5 & 5 & 5 & 1 & 25 & 4.2 \\
\hline S5 & 3 & 5 & 5 & 3 & 3 & 1 & 20 & 3.3 \\
\hline
\end{tabular}

Then there were $\mathrm{S} 3$ and $\mathrm{S} 4$ who got the same score 19,2 with an average of 9,6. Then, S5 has a total score of 17,3 and gets an average of 2,9. And the last one, S6 has a total of 17,2 with an average of 2,87. The researchers planned to interview six students (S1-S6), unfortunately S6 was very difficult to reach. The researchers have tried to contact him via all social media owned by S6 but there is no response from the student. Therefore, the researchers decided to continue the research with five participants (S1 - S5) to be interviewed. Table 3 is an example of the students 'speaking assessments with the topic "I'm a moderator in a seminar". Based on the speaking performance result by using the speaking rubric as the pattern, it can be explained that S1-S4 have the same score in the pronunciation aspect. S1 gets a value of 4 because even though she has a particular accent, every word pronounced by S1 always sounds clear.
S2's way of pronounced the words is always intelligible, even though she spoke relatively fast. S3 seemed to be very careful in pronouncing every word. It made the words can be heard clearly. S4's intonation was precise. So, every word is easy to understand even if she has her own speaking style. Meanwhile, S5 got the lowest score in pronunciation with 3 points. There were a few words that were mispronounced by S5. For example: great (greit), but S5 pronounced it greet (gri:t). Another example like chance (tfa:ns), but she pronounced it change (tferndz).

In addition, the S1-S5 got the perfect score on grammar and vocabulary aspects. There is no grammar error in their speaking performance. For vocabulary, S1S5 chose the appropriate vocabulary in accordance with the context, e.g., "Ladies and gentlemen, now we come to the questions and answers session." 
Furthermore, in the fluency aspect, S4 got the highest score among them. S4 has a steady pace from the beginning to the end of the sentence. S1-S3 has the same value for the fluency aspect, which is 3 points. $\mathrm{S} 1$ spoke quite fluently, but some sentences repeated. So, she was a little stammering, "Do you ... do you have any questions?". S2 didn't take video in one take. She took the video with several takes, so it was a consideration in assessing her fluency. The pace of speech was pretty fast but still sounds clear. S3 spoke at a fairly slow pace among other students. He also repeated a sentence, and it sounded like he was stammering "without further ... without further ado". And then S5 got the lowest point with 3. S5 often looked to the text, so it is more like reading. She also repeated the word "inspira..ins..inspiration".

In nonverbal aspects such as facial expressions and gestures, the facial expressions showed by $\mathrm{S} 1$ often match the emotions expressed, e.g., she greeted seminar participants with a smile. S2 didn't show many facial expressions that matched the message being conveyed. S3's facial expressions frequently matched the emotions expressed. Although sometimes, he glanced up because he saw the text. S4 consistently showed a facial expression that matched the emotion she conveyed. S5 was too focused on recording the video so that the facial expressions she showed periodically matched the emotions expressed.

In addition, S1, S4, and S5 got 1 point for the gesture's aspect. S1 didn't use gestures at all. From start to finish of the video, she just straightened her arms. Similar to S1, S4 And S5 didn't show any gestures. S2 got 2 points for gestures. At the beginning of the video, $\mathrm{S} 2$ showed a motion that allowed the speaker to speak. But, throughout the video, she always held her hands together and then clenched them. S3 got the highest score in the gesture's aspect with 3 points. Many of the gestures shown by S3 matched the message he conveyed. But, most of the gestures were not fully visible because of the video angle. By using the features in Flipgrid, such as closed captions (CC), teacher's feedback and peer feedback, students' speaking skills can be strengthened. The $\mathrm{CC}$ feature in Flipgrid can make students pay more attention to their pronunciation in speaking. The closed captions are automatically captioned by Flipgrid. So, if several sentences do not match the captions, students can improve their pronunciation.

Based on the students' interviews, most of them claimed that they felt their speaking ability had improved. From five participants, three participants stated they were better in several speaking aspects. S2 stated that her fluency had increased because before recording the video, she has to repeat herself multiple times, and it helps her not to stutter while speaking. In agreement with S2, S4 also revealed that besides taking video, she did a lot of practice and paid more attention to pronunciation, choice of word, etc. Other participants, $\mathrm{S} 5$, stated that her pronunciation increased because she checks the pronunciation in a dictionary before recording the video. This is in line with Dyer (2015), who claimed that video recording includes students in the learning process by enabling them to view their recording and recognise their speech strengths and areas for improvement. This can contribute to enhanced skills (Dyer, 2015). Different statements come from S3 and S1. S3 stated that Flipgrid is just a media where you can submit your work. S1 and S3 argued that the feedback feature where the user can give the other work feedback might improve speaking skills. However, they are not sure whether their speaking skills have improved or not. Besides, students were asked about their experience using Flipgrid in speaking class. There are various answers from S1-S5. S1 stated that in this pandemic situation, Flipgrid is a suitable platform to use for online learning. With Flipgrid, students can use short videos to have online discussions, allowing them to see and respond to each other as they participate in the discussion (Green \& Green, 2018). To support S1's statement, S2 also added that Flipgrid is a convenient way for lecturers to assess our speaking ability. The finding is similar to MacIsaac (2020), who claimed that Flipgrid is an easy to use and free classroom video site.

Meanwhile, S3, S4, and S5 have a similar experience using Flipgrid. S3 claimed that Flipgrid is easy to use since the app is quite simple. Moreover, S4 and S4 stated that they enjoy using Flipgrid in speaking class. This is similar to the advantages of Flipgrid, as described by Stoszkowski (2018). In terms of the appeal, Flipgrid has an advantage. Students tend to prefer to hear each other speaking on a video rather than read the written text, which they think is time-consuming and tiresome. From the interview results, it can be concluded that most students feel that their speaking ability has enhanced due to feedback from teachers and friends so that it can make students improve their speaking aspects to be even better. Besides, after doing the repetition many times before recording the video, it also helped the students to enhance their fluency aspect.

This study showed that students' speaking skills improved, but not entirely because of the use of Flipgrid's features, the main reason is because they had to record and upload their videos to Flipgrid. So, to avoid making errors while filming a video, they have to consider and practice what they want to express in the video. By selecting the words to convey, they may develop their vocabulary and grammar skills. And the fluency aspect can also increase because they do a lot of repetition before recording the video. As described in the Findings section, the participant checks the dictionary to see how those words can be pronounced for the pronunciation aspect. Besides, their facial expressions and gestures are also enhanced because they have 
learned what they want to express and make facial expressions and gestures appear more natural and suit the messages being expressed.

\section{CONCLUSION}

Flipgrid is a video chat platform designed to participate in video and audio recording conversations easily. Discussions or conversations around the group are spread equally by Flipgrid, which increase speaking time, pronunciation, and communication among students.

The result indicates that students ' speaking skills could be strengthened by using Flipgrid as a forum to upload their speaking video. It was noticed that there was an effect on the student's speech performance in this class. The students claimed that their fluency, pronunciation, grammar, vocabulary, facial expressions, and gestures were improved while using Flipgrid. Students acknowledged that the platform was easy to use and helped them practice more. However, the findings of this study cannot be seen as a standard that all students using Flipgrid can enhance their speaking skills. Therefore, this study suggests that further research needs to be carried out on Flipgrid so that the effect of Flipgrid on students' speaking ability can be explored more.

\section{REFERENCES}

Alharbi, H. A. (2015). Improving students' English speaking proficiency in saudi public schools. International Journal of Instruction, 8(1), 105-116.

Al-Jamal, D. A., \& Al-Jamal, G. A. (2014). An investigation of the difficulties faced by EFL undergraduates in speaking skills. English Language Teaching, 7(1), 19-27. doi:10.5539/elt.v7n1p19

Anderson, C., \& Delmonico, R. (2016). Assessment rubric. Retrieved from https://www.northernspeech.com/uploads/cmc_sect ion_3_8_assessment_rubric.pdf

Creswell, J. W. (2012). Educational research: Planning, conducting, and evaluating quantitative and qualitative research (4th ed.). Boston, MA: Pearson.

Dettinger, M. (2018). Flipgrid. Baton Rouge: Software Reviews.

Dhull, I., \& Sakshi. (2017). Online learning. International Education \& Research Journal [IERJ], $3(8)$, 32-34.
Dyer, K. (2015, July 21). The importance of student self assessment. Retrieved from https://www.nwea.org/blog/2015/the-importanceof-student-self-assessment/

Emilia, E. (2009). Menulis thesis dan disertasi. Bandung: Alfabeta.

Green, T., \& Green, J. (2018). Flipgrid: Adding voice and video to online discussions. TechTrends, 62(1), 128-130. doi:10.1007/s11528-017-0241-x

Harris, D. P. (1969). Testing English as a second language. New York: Mc. Graw Hill.

Hennink, M., Hutter, I., \& Bailey, A. (2020). Qualitative research methods (2nd ed.). SAGE Publications. [Google Books version]. Retrieved from https://books.google.co.id/books?id=_InCDwAAQ BAJ $\& d q=$ definition + of + qualitative + methods $\& 1 \mathrm{r}=\&$ source $=g b s \_n a v l i n k s \_s$

Kayi, H. (2006). Teaching speaking: Activities to promote speaking in a second language. The internet TESL journal, 12(11), 1-6. Retrieved from http://iteslj.org/Techniques/Kayi-

TeachingSpeaking.html

Keiper, M. C., White, A., Carlson, C. D., \& Lupinek, J. M. (2020). Student perceptions on the benefits of Flipgrid in a HyFlex learning environment. Journal of Education for Business, 1-9. doi:10.1080/08832323.2020.1832431

MacIsaac, D. (Ed.). (2020). Flipgrid. com-An easy-touse free classroom student video site (website and smartphone app). The Physics Teacher, 58(4), 286. doi:10.1119/1.5145485

Mahmoudi, S., \& Mahmoudi, A. (2015). Internal and external factors affecting learning english as a foreign language. International Journal of Language and Linguistics, 3(5), 313-322.

Stoszkowski, J. (2018). Using flipgrid to develop social learning. Compass: Journal of Learning and Teaching, 11(2), 1-4.

Theoris, L. (2017). Flipgrid: video discussion tool for fostering a community of learners. Retrieved from https://www.learning-theories.com/flipgrid-videodiscussion-tool-fostering-community-learners.html

Tuan, N. H., \& Mai, T. N. (2015). Factors affecting students' speaking performance at le thanh hien high school. Asian Journal of Educational Research, 3(2), 8-23.

Tuyet, T. T. B., \& Khang, N. D. (2020). The influences of flipgrid app on viatnamese EFL high school learners' speaking anxiety. European Journal of 
Foreign Language Teaching, 5(1), 128-149. doi:10.46827/ejfl.v5i1.3264

UNESCO. (2020). 290 million students out of school due to COVID-19: UNESCO releases first global numbers and mobilizes response. Retrieved from https://en.unesco.org/news/290-million-students- out-school-due-covid-19-unesco-releases-firstglobal-numbers-and-mobilizes

UNESCO. (2020). COVID-19 educational disruption and response. Retrieved from https://en.unesco.org/covid19/educationresponse 